\title{
Four cases of human infection with Achromobacter anitratus
}

\author{
D. J. B. ASHLEY AND W. KWANTES \\ From Morriston Hospital and Public Health Laboratory, Swansea
}

SYNOPSIS Four cases of human infection with Achromobacter anitratus, one of which was fatal, are described. They all occurred at one hospital within a period of two months.

The bacteriology, antibiotic sensitivity, and pathogenicity of the organisms are discussed. One of the strains was found to differ from the other three.

Achromobacter anitratus is rarely reported as the causative organism in human infections. We could find only six fatal cases described in the literature, four of them in one article (Lutz, Grootten, Velu, and Velu, 1956) and the other two individually (Ferguson and Roberts, 1950; Gardner, Pines, and Stewart, 1960). We record four instances of infection with this organism, one of which was fatal, from the practice of one hospital during a period of two months.

\section{CASE REPORTS}

CASE 1 A man of 55 was admitted urgently suffering from severe abdominal pain and nausea. There was no history of dyspepsia or of previous similar attacks of pain. On examination the abdomen was as rigid as a board and he was noted to have generalized neurofibromatosis. At laparotomy there was free bile-stained fluid in the abdominal cavity and generalized peritonitis. No cause for the peritonitis was found, there was no peptic ulcer and no perforation of the bowel, the appendix was healthy, and, apart from containing a few small stones, the gall bladder appeared normal. There were no herniae and no diverticulae of the bowel. The abdomen was closed with drainage; the drainage fluid contained large amounts of amylase and some bile and the serum amylase content was high (1,000 units); these results suggested a biliary and pancreatic fistula. The condition of the patient deteriorated despite supportive and antibiotic therapy and one month after the operation he died. Achromobacter anitratus associated with $E$. coli was isolated on several occasions from the drainage fluid. Post-mortem examination was carried out the day after death. The principal findings were as follows:-

There was generalized neurofibromatosis affecting the superficial nerves of the skin and also the nerves of the abdominal viscera. There was an abscess in the lesser sac of the peritoneum. The liver was enlarged and contained $\bar{Z}$ many micro-abscesses which were shown on histological section to be related to ascending infection of the bile $\frac{\Phi}{3}$ ducts. The pancreas was firm but not enlarged; there were no areas of fat necrosis. The pancreatic ducts were dilated and there was a fistula between a major pancreatic duct $\vec{\theta}$ and the abscess cavity in the lesser sac. There was a neurofibromatous nodule in the duodenal mucosa adjacent and just proximal to the ampulla of Vater, compressing the pancreatic and bile ducts.

There was a moderate degree of chronic bronchitis $\bar{\partial}$ and emphysema. The heart was normal, but there was well marked atheroma in the cerebral and coronary $\mathbb{D}$ vessels. Achromobacter anitratus was isolated in pure culture from the liver, the subphrenic abscess, and the abdominal sinus. This organism was not isolated from the blood, the general peritoneal cavity, or from the lungs.

CASE 2 A woman aged 75 was admitted to hospital for treatment of a fracture of the neck of the right femur. The fracture was reduced and secured by internal fixation; 14 days after operation superficial infection of the operation wound was noted and she also had a small bedsore. Infection was confined to the most superficial $ᄋ$ tissues and it was at no time necessary to re-open the $D$ wound. Local treatment with acriflavine in spirit was used and both the bedsore and the wound infection healed completely before the patient was discharged $\mathbb{O}$ from hospital.

Achromobacter anitratus was isolated from the operation wound and from the bedsore, in each instance in association with coagulase-negative staphylococci.

CASE 3 A man aged 23 was admitted suffering from an abscess in the superficial tissues of the perineal region. The lesion was draining at the time of admission. It was treated by local applications of kaolin poultices and dressings and healed satisfactorily.

Achromobacter anitratus was isolated in pure culture from this abscess. 
CASE 4 A man aged 41 was admitted for arthrodesis of the ankle after a compound fracture which had led to painful arthritis. On admission he was found to have a minor infection of the old wound and operation was deferred. Achromobacter anitratus was isolated in pure culture from this lesion, which healed without event.

\section{DESCRIPTION OF ACHROMOBACTER ANITRATUS}

All four strains were small Gram-negative coccobacilli possessing capsules. All were non-motile. All grew well on unenriched media and MacConkey agar at room temperature and $37^{\circ} \mathrm{C}$. but did not grow on deoxycholatecitrate agar or S.S.agar. There was slight haemolysis on horse-blood agar. No growth occurred anaerobically. On nutrient agar after 24 hours at $37^{\circ} \mathrm{C}$. the colonies were circular, about $1 \mathrm{~mm}$. in diameter, convex, smooth and glistening with an entire edge; they were greyish white, moderately opaque, iridescent, of a butyrous consistency and emulsified easily. Detailed biochemical reactions are given in Table $I$.

\section{TABLE I}

BIOCHEMICAL REACTIONS OF STRAINS OF ACHROMOBACTER ANITRATUS

Case 1

Case 2

Case 3

Case 4

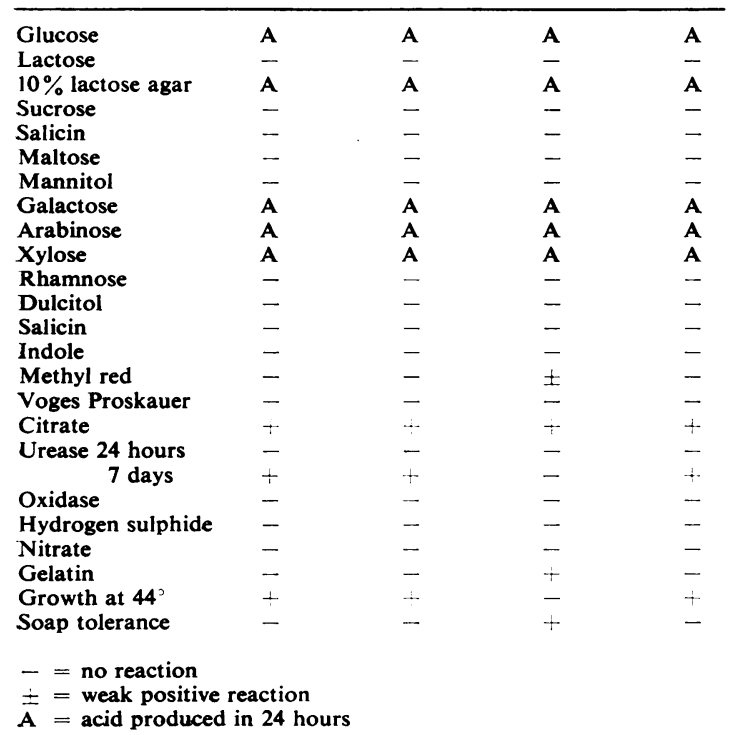

The sugar reactions were carried out in peptone water with $1 \%$ added sugar with $0.01 \%$ phenol red indicator; incubation was at $37^{\circ} \mathrm{C}$. and all tubes were kept for 21 days. The $10 \%$ lactose agar medium recommended by Chilton and Fulton (1946) was used in addition. The indole, methyl red, Voges Proskauer, oxidase, and citrate utilization tests were carried out by the techniques of Mackie and McCartney (1960). Urea hydrolysis was tested on the medium described by Christensen (1946); the tubes were incubated at $37^{\circ} \mathrm{C}$. and examined after 24 hours and seven days. Hydrogen sulphide production was tested in Kligler's iron agar medium. Nitrate reduction was tested both in broth culture (Wilson and Miles, 1955) and by a plate method (Cook, 1950). Gelatin liquefaction was investigated by growing the organism in this medium at room temperature. Growth at $44^{\circ}$ was tested in nutrient broth, and the soap tolerance was tested on $10 \%$ soap agar plates (Billing, 1955).

\section{ANIMAL PATHOGENICITY}

Animal pathogenicity was determined in both mice and guinea-pigs. An overnight broth culture was made and $0.5 \mathrm{ml}$. was inoculated intraperitoneally into each of four mice and $1 \mathrm{ml}$. into each of two guinea-pigs. Strains from Cases 1 and 4 were pathogenic for both mice and guineapigs, the animals dying within 24 hours; large numbers of Achromobacter anitratus were recovered from the peritoneal cavity and spleen and heart blood. The strain from Case 2 was pathogenic for mice but not guinea-pigs and the strain from Case 3 was not pathogenic for either of these species. The strain from Case 3 differed from the other three strains in its absence of pathogenicity, its ability to liquefy gelatin, its tolerance of soap, and its failure to grow at $44^{\circ} \mathrm{C}$. This strain was agglutinated by a serum prepared at the Central Public Health Laboratory against a gelatin-liquefying strain of Achromobacter anitratus isolated in 1953 from an abscess. This serum did not agglutinate the strains isolated from Cases 1, 2, and 4. Billing (1955) stated that her gelatin-liquefying, soaptolerant strains were not pathogenic, although two out of her 31 strains were obtained from pathological material. Our strain was isolated in pure culture from an ischiorectal abscess, which suggests that it was mildly pathogenic. Its absence of pathogenicity for laboratory animals does, however, suggest a pathogenicity lower than that of the other strains.

\section{ANTIBIOTIC SENSITIVITY}

Sulphonamide sensitivity was tested on lysed $5 \%$ horse blood agar using a commercial disc. Determination of the antibiotic sensitivities was carried out on nutrient agar plates also using commercial discs. The results are summarized in Table II. Table III shows the variability of the results of sensitivity on Achromobacter anitratus reported in the literature (Moor, 1949; Brooke, 1951; Waage, 1953; Lund, 1954; Lutz et al., 1956; Gardner et al., 1960). Most strains are resistant to sulphonamides and to the antibiotics penicillin and chloramphenicol;

TABLE II

ANTIBIOTIC SENSITIVITY OF ACHROMOBACTER ANITRATUS

\begin{tabular}{|c|c|c|c|c|}
\hline & Case 1 & Case 2 & Case 3 & Case 4 \\
\hline 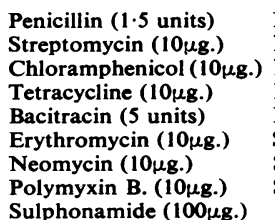 & $\begin{array}{l}\text { Resistant } \\
\text { Resistant } \\
\text { Resistant } \\
\text { Resistant } \\
\text { Resistant } \\
\text { Sensitive } \\
\text { Sensitive } \\
\text { Sensitive } \\
\text { Resistant }\end{array}$ & $\begin{array}{l}\text { Resistant } \\
\text { Resistant } \\
\text { Resistant } \\
\text { Resistant } \\
\text { Resistant } \\
\text { Sensitive } \\
\text { Sensitive } \\
\text { Sensitive } \\
\text { Resistant }\end{array}$ & $\begin{array}{l}\text { Resistant } \\
\text { Sensitive } \\
\text { Resistant } \\
\text { Sensitive } \\
\text { Resistant } \\
\text { Sensitive } \\
\text { Sensitive } \\
\text { Sensitive } \\
\text { Resistant }\end{array}$ & $\begin{array}{l}\text { Resistant } \\
\text { Resistant } \\
\text { Resistant } \\
\text { Resistant } \\
\text { Resistant } \\
\text { Resistant } \\
\text { Sensitive } \\
\text { Sensitive } \\
\text { Resistant }\end{array}$ \\
\hline
\end{tabular}


TABLE III

\begin{tabular}{|c|c|c|c|c|c|c|c|}
\hline \multicolumn{8}{|c|}{ ANTIBIOTIC SENSITIVITY OF ACHROMOBACTER ANITRATUS } \\
\hline & $\begin{array}{l}\text { Moor } \\
\text { (1949) }\end{array}$ & $\begin{array}{l}\text { Brooke } \\
(1951)\end{array}$ & $\begin{array}{l}\text { Waage } \\
(1953)\end{array}$ & $\begin{array}{l}\text { Lund } \\
\text { (1954) }\end{array}$ & $\begin{array}{l}\text { Lutz et al. } \\
\text { (1956) }\end{array}$ & $\begin{array}{l}\text { Gardner, Pines, } \\
\text { and Stewart } \\
(1960)\end{array}$ & $\begin{array}{l}\text { Ashley and } \\
\text { Kwantes } \\
\text { (Present Series) }\end{array}$ \\
\hline $\begin{array}{l}\text { Strains } \\
\text { Sulphonamide }\end{array}$ & $\begin{array}{l}15 \\
\mathrm{R}\end{array}$ & $\begin{array}{r}86 \\
\text { S } 15\end{array}$ & $\begin{array}{l}1 \\
\mathbf{R}\end{array}$ & $\begin{array}{l}77 \\
60 \% R\end{array}$ & 7 & $\begin{array}{l}1 \\
S\end{array}$ & $\begin{array}{l}4 \\
\mathbf{R}\end{array}$ \\
\hline Penicillin & $\mathbf{R}$ & $\begin{array}{ll}R & 71 \\
S & 1 \\
\text { R } & 85\end{array}$ & $\mathbf{R}$ & $\mathbf{R}$ & $\mathbf{R}$ & $\mathbf{R}$ & $\mathbf{R}$ \\
\hline Streptomycin & $\mathbf{S}$ & $\begin{array}{l}\text { S } 43 \\
\text { R } 43\end{array}$ & $\mathbf{s}$ & $39 \% \mathbf{R}$ & & $\mathbf{R}$ & $\begin{array}{l}1 \mathbf{S} \\
3 \mathbf{R}\end{array}$ \\
\hline Chloramphenicol & & $\begin{array}{l}\text { S } 1 \\
\text { R } 85\end{array}$ & $\mathbf{s}$ & $95 \% \mathbf{R}$ & $\mathbf{R}$ & $\mathbf{R}$ & $\mathbf{R}$ \\
\hline Chlortetracycline & & $\begin{array}{l}\mathbf{S} 81 \\
\mathbf{R} 5\end{array}$ & $\mathbf{R}$ & $\mathbf{s}$ & & $\mathbf{R}$ & \\
\hline Tetracycline & & $\begin{array}{l}S \quad 76 \\
\text { R } 10\end{array}$ & $\mathbf{R}$ & $98 \% \mathrm{~S}$ & Variable & & $\begin{array}{l}3 \mathrm{R} \\
\mathbf{1 S}\end{array}$ \\
\hline Erythromycin & & & & $88 \% \mathbf{R}$ & $\mathbf{R}$ & & $\begin{array}{l}3 \mathrm{~S} \\
1 \mathrm{R}\end{array}$ \\
\hline $\begin{array}{l}\text { Bacitracin } \\
\text { Neomycin } \\
\text { Spiramycin }\end{array}$ & & & & $\begin{array}{l}\mathbf{R} \\
\mathbf{S}\end{array}$ & $\begin{array}{l}\mathbf{R} \\
\mathbf{S} \\
\mathbf{R} \\
\mathbf{S}\end{array}$ & & $\begin{array}{l}\mathrm{R} \\
\mathrm{S}\end{array}$ \\
\hline Polymyxin B & & & & & & & $\mathbf{S}$ \\
\hline
\end{tabular}

sensitivity to streptomycin and the tetracycline group is variable and there appears to be uniform sensitivity to neomycin and uniform resistance to bacitracin.

\section{EPIDEMIOLOGY}

These cases occurred independently of each other; all were in different wards of the hospital and were under the care of three separate surgeons. One surgeon had two of the patients under his care, but these were admitted at an interval of nearly two months to widely separated wards. There were no nurses or doctors common to any of the patients who were in hospital at the same time and there was no known contact between the patients outside the hospital before admission.

\section{DISCUSSION}

Achromobacter anitratus is a little known organism belonging to the tribe Achromobactereae. Schaub and Hauber (1948) examined 15 strains and reported on the biochemical and serological characteristics of the organism. They proposed the name Bacterium anitratum. Further consideration of the taxonomy of this group of organisms has led to the adoption of the currently accepted name Achomobacter anitratus (Billing, 1955).

The organism is a Gram-negative bacillus, usually coccobacillary in form, and often resembling organisms of the genus Neisseria from which it may be distinguished by the negative oxidase reaction. It closely resembles the organism described by von Lingelsheim $(1906,1908)$ who isolated from the cerebrospinal fluid an encapsulated organism which he called Diplococcus mucosus. Several authors have isolated further strains of Diplococcus mucosus from specimens of cerebrospinal fluid and have noted that they were capable of growth on MacConkey agar
(Cowan, 1938; McFarlan, 1941). Seeliger (1953) regards the recently recognized Achromobacter anitratus and Diplococcus mucosus as identical but the ability of the strains of the latter organisms isolated by Cowan (1938) to reduce nitrates suggests a separate identity.

Piéchaud, Piéchaud, and Second (1951, 1956) included this organism in the genus Moraxella and renamed it Moraxella glucidolytica whereas Ewing (1949) proposed its inclusion in the tribe Mimeae genus Herellea (De Bord, 1939, 1942). Henriksen (1952, 1960) has reviewed strains of Achromobacter anitratus from the viewpoint of taxonomy. He showed that representative strains of this organism have little resemblance to members of the genus Moraxella and placed them in the tribe Achromobactereae. He also mentioned the resemblance of Achromobacter anitratus to the Herellea genus but questioned the validity of the tribe Mimeae.

Despite its unusual nature $A$ chromobacter anitratus is easily identified. It appears on primary isolations or on subculture as a non-lactose fermenting colony on MacConkey's medium with a characteristic cocco-bacillary morphology. Further con- N firmation of its identity is made by the sugar $N$ reactions; it produces acid in glucose but, as it is $N$ strictly aerobic, the fermentation is seen to be $\underset{\sigma}{\sigma}$ greater in the upper part of the tube and there is no fermentation at all in the Durham's tube. The routine $\stackrel{\circ}{工}$ sugars-mannitol, lactose, sucrose, and dulcitol-are $\stackrel{\$}{+}$ not fermented and no indole is produced. Finally its ability to utilize citrate, the negative oxidase reaction and its failure to reduce nitrates confirm its identity. For this last test we have found the nitrate plate $\frac{?}{\mathbb{D}}$ described by Cook (1950) of great value. 
The natural habitat of the organism is uncertain. Isolations have been made from faeces and urine of apparently normal people (Philpot, 1956; Billing, 1955) and a variant tolerant of soap has been isolated from face flannels and sponges (Billing, 1955). It is usually regarded as of low pathogenicity (Wilson and Miles, 1955) but a number of instances of human infection have been recorded and strains have been found to be pathogenic to mice, guinea-pigs, and rabbits (Schaub and Hauber, 1948; Stuart, Formal, and McGann, 1949; Lutz et al., 1956, and the present series) although contrary findings have also been recorded (Brooke, 1951; Waage, 1953).

Stuart and Van Stratum (1945) isolated Achromobacter anitratus from the faeces of 10 infants involved in a small outbreak of gastroenteritis and further association with gastroenteritis was noted by Stuart et al. (1949). It must, however, be remembered that at this time the role played in the aetiology of gastroenteritis by the 'specific' strains of $E$. coli was not recognized and these isolations may have been of commensal organisms. Other reports of human infection with this bacterium have covered a wide range of clinical disorders. In most cases the report was directed to the bacteriology of the strain and clinical data are scanty. One common feature, however, has been the concurrent isolation of other organisms, often of the coli group (Rocha and Guze, 1957). Moor (1949) described a series of 15 cases of conjunctivitis from which Achromobacter anitratus was isolated in pure culture. He noted that several of the cases had occurred among patients consulting the same ophthalmologist and suggested the possibility of cross-infection. Inoculation of cultures of the organism into the eyes of rabbits induced a mild conjunctivitis from which, however, no bacterial growth was obtained and similar experiments on cats showed no pathogenic effect.

There have been several fatalities following infection of the meninges after cranial operation (Lutz et al., 1956). A recent fatal case was described in 1960 by Gardner et al. Their patient had suffered from chronic bronchitis for many years and died rapidly from a fulminating pneumonia and septicaemia. Achromobacter anitratus was isolated in a heavy growth from the sputum and was seen in smears of bronchial pus at necropsy. Case 1 is another fatality recorded of infection with this organism. In all of these cases infection with Achromobacter anitratus has supervened upon a serious pre-existing disease such as chronic bronchitis or chemical peritonitis due to the release of biliary and pancreatic enzymes into the peritoneum or upon a cranial operation. This association with other disease is seen also in the non-fatal cases recorded. The three patients of Rocha and Guze (1957), in whom the organism appeared to play a major role, were suffering from cirrhosis of the liver, operation for closure of a patent ductus arteriosus, and renal calculus associated with severe paralytic poliomyelitis respectively. These observations and the common association of Archromobacter anitratus with other organisms suggests that the organism is of low pathogenicity towards man.

\section{REFERENCES}

Billing, E. (1955). J. gen. Microbiol., 13, 252.

De Bord, G. G. (1939). J. Bact., 38, 119.

(1942). Iowa St. Coll. J. Sci., 16, 471.

Brooke, M. S. (1951). Acta path. microbiol. scand., 28, 338.

Chilton, M. L., and Fulton, M. (1946). J. Lab. clin. Med., 31, 824.

Christensen, W. B. (1946). J. Bact., 52, 461.

Cook, G. T. (1950). J. clin. Path., 3, 359.

Cowan, S. T. (1938). Lancet, 2, 1052.

Ewing, W. H. (1949). J. Bact., 57, 659.

Ferguson, W. W., and Roberts, L. F. (1950). Ibid., 59, 171.

Gardner, D. L., Pines, A., and Stewart, Sheila M. (1960). Brit. med. $J ., 1,1108$.

Henriksen, S. D. (1952). J. gen. Microbiol., 6, 318.

- (1960). Int. Bull. bact. Nomencl., 10, 23.

Lingelsheim, W. von (1906). Klin. Jb., 15, 373.

(1908). Z. Hyg. Infekt.-Kr., 59, 457.

Lund, E. (1954). Acta path. microbiol. scand., 34, 329.

Lutz, A., Grootten, O., Velu, M., and Velu, H. (1956). Rev. Immunol. (Paris), 20, 215.

Mackie, T. J., and McCartney, G. E. (1960). Handbook of Bacteriology, 10th ed., ed. R. Cruickshank. Livingstone, Edinburgh.

McFarlan, A. M. (1941). J. Path. Bact., 53, 446.

Moor, W. A. (1949). Amer. J. Ophthal., 32, 1593.

Piéchaud, D., Piéchaud, M., and Second, L. (1951). Ann. Inst. Pasteur, 80, 97.

(1956). Ibid., 90, 517.

Philpot, V. B. Jr. (1956). J. Urol. (Baltimore), 75, 562.

Rocha, H., and Guze, L. B. (1957). A.M.A. Arch. intern. med., 100, 272.

Schaub, I. G., and Hauber, F. D. (1948). J. Bact., 56, 379.

Seeliger, H. (1953). Zbl. Bakt. I. Abt. Orig.)., 159, 173.

Stuart, C. A., and Van Stratum, E. (1945). J. Pediat., 26, 464.

- Formal, S., and McGann, V. (1949). J. infect. Dis., 84, 235.

Waage, R. (1953). Acta path. microbiol. scand., 33, 268.

Wilson, G. S., and Miles, A. A. (1955). Topley and Wilson's Principles of Bacteriology and Immunity, Vol. 1, p. 451. 4th ed. Arnold, London. 